\title{
Report
}

\section{Nuclear Legislation System and Nuclear Program Outlook in Thailand}

\author{
Apisara Charoensri, ${ }^{* 1, * 2}$ Mikhail N. Morev, ${ }^{* 2}$ Hidenori ImaZu, ${ }^{* 2}$ Takeshi Imoto*3 and Toshiso Kosako*2
}

(Received on August 4, 2008)

(Accepted on December 16, 2008)

\begin{abstract}
In Thailand, radioactive materials are widely used for the industry, medicine, research and development fields. Reported here are background and recent developments in the national nuclear legislation system, including regulation of radiation safety and current status of nuclear program in Thailand. Under the Atomic Energy for Peace Act, the Thai Atomic Energy Commission (Thai AEC) is authorized to approve regulations respecting, the conversion, enrichment, processing, reprocessing, possession, import, export, use, packaging, transport, management and storage of nuclear materials. The most recent developments are related to the New Ministerial Regulation on Licensing Requirements Procedures and Nuclear Material, By-Product or Atomic Energy Processing B. E 2550 (A. D. 2007) issued under the Atomic Energy for Peace Act, B. E. 2504 (A. D. 1961). Currently, the Thai Cabinet is discussing the draft new Atomic Energy for Peace Act which is to revise the Act. The draft Act is to sets forth criteria for protecting individuals, society and the environment from radiation hazards with the perspective for anticipated nuclear power sector development in Thailand.
\end{abstract}

KEY WORDS: Nuclear Legislation, radiation safety, Atomic Energy for Peace Act, Thai Atomic Energy Commission, Thai Cabinet, Thailand.

\section{INTRODUCTION}

After the United Nations had adopted the International Atomic Energy Agency Statute on October 26, 1956 and founded the International Atomic Energy Agency, the Thai Government ratified the statutes of IAEA on October 15, 1957 and consequently was $58^{\text {th }}$ on the list of IAEA member states. ${ }^{1)}$ Many countries have accepted the use of atomic energy to benefit in the quality of life of their population. This led to the IAEA Atoms for Peace program, which requires a responsible agency to ensure accurate, appropriate and safe utilization of atomic energy for both the users and the public.

For decades, Thailand has been one of countries utilizing atomic energy for research and industry. The currently existed regulatory infrastructure is considered to be sufficient for these applications, which include operation of one research reactor, medical facilities, industrial use, and etc. Nevertheless, anticipated future ambitious development of the national nuclear sector, specifically the construction and operation of a first nuclear power plant, will require significant improvements of the regulatory infrastructure.

\footnotetext{
*1 Technical Group, Office of Atoms for Peace; Vibhavadi-Rangsit Rd., Bangkok 10900, Thailand.

*2 Department of Nuclear Engineering and Management, Graduate School of Engineering, The University of Tokyo; 2-11-16, Yayoi, Bunkyo-ku, Tokyo 113-0032, Japan.

E-mail: apisara@n.t.u-tokyo.ac.jp

*3 Division for Environment, Health and Safety, The University of Tokyo; 7-3-1, Hongo, Bunkyo-ku, Tokyo 113-8654, Japan.
}

So far, there have never been any significant nuclear incidents detected at the Thai Research Reactor-1 (TRR-1), since our knowledgeable and skilled staff operates the reactor under strict safety control. However, we have experienced a serious radiation accident with dispersion of a strong cobalt- 60 source in 2,000. It happened after a canister containing cobalt-60 used in a radiotherapy machine for treating cancer patients was stolen. Ignorant of radiological hazard, a scrap dealer wrenchingly opened the canister which resulted in dispersion of radioactive materials, twelve injured and three lethal outcomes. ${ }^{1)}$

Though most people find atomic energy fear-provoking and difficult to understand, atomic energy plays important roles in many aspects of our lives. Many of us may have used applications of nuclear energy without knowing it. This is because today nuclear technology, radioisotopes, and radiation techniques have valid applications in many fields including agriculture, industry and medicine. So that, the quality of life and our environment relies on nuclear and radiation safety, in general, and specifically on the quality of regulatory controls. ${ }^{1)}$

The purpose of this article is to show the present situations of nuclear legislation system and nuclear program in Thailand. This information will be effective for future mutual corporation between Thailand and Japan.

\section{RELEVANT LEGISLATIONS}

Atomic energy utilization directly impacts the public, both in positive and negative ways. Obviously, the public benefit from the use of nuclear technology to improve their quality of 
life via outputs from industrial, agricultural, and medical sectors. Without regulations, the public are vulnerable to dangers posed by improper use of nuclear technology.1)

Thailand economy is growing rapidly, which in turn requires secure power supply to satisfy the needs of growing industry. Nuclear power plants are being considered as a viable option because current nuclear technologies are both safe and competitive as compared to other alternatives. One of the key prerequisites for of safe atomic energy use is the adequate legislation and regulatory system. Ideally, the regulatory developments should precede real activities in the nuclear industry to provide for its safe and efficient implementation. The sections below briefly describe the history of the establishment of legislative basis for Thai nuclear sector and the recent developments in the regulatory infrastructure in line with foreseen construction of first nuclear power plant.

\section{The History of Nuclear Legislation in Thailand}

On November 17, 1954, the Government of Thailand appointed the Thai Atomic Energy Commission (Thai AEC) with a function to receive official delegation of the U.S. Senate Affiliated Atomic Energy Commission and negotiate the plan concerning joining the of Atomic Energy for Peace program. As a result, the Government of Thailand assigned the Thai AEC to be responsible for and carry out all matters related to atomic energy for the civil purposes henceforth.

On April 21, 1956, the Cabinet renamed the Thai AEC as the "Thai Atomic Energy Commission for Peace" and assigned it to be responsible for and establish the foundation of all activities in field of nuclear energy in Thailand; regulatory roles pursuant to the Atomic Energy for Peace Act (define policy on utilization of nuclear energy, set up standards, lay down rules for control and implementation of activities subject to licensing, etc.), advise and provide recommendations on nuclear safety measures to the Government and promoting the dissemination of knowledge relating to atomic energy. ${ }^{1)}$

In 1960, the Thai Cabinet approved a request by the Thai AEC for construction of the first nuclear research reactor at the Kasetsart University Complex. The reactor was named the Thai Research Reactor-1 (TRR-1). ${ }^{1)}$

On April 25, 1961, the Royal Thai Government proclaimed the enactment of the Atomic Energy for Peace Act, B. E. 2504 (A.D. 1961). ${ }^{1)}$ This Act regulates safe atomic energy utilization until now. The act set up the Thai AEC to take responsibility for formulating policies and strategic plans on atomic energy utilization and regulating safe utilization according to technical procedures (standards). ${ }^{1)}$ The act also established the Office of Atomic Energy for Peace (OAEP), under the Prime Minister's Office. This is considered as the starting point for the creation of the national agency responsible for civil atomic energy utilization in Thailand.

In addition to the Atomic Energy for Peace Act, which is the basic low, it is necessary to have other ministerial regulations to define details of the regulation such as conditions, licensing procedures, standard, and radioactive waste management procedures in order to efficiently regulate the safe utilization of atomic energy.
According to the Governmental Division Restructuring Act B. E. 2545 (A. D. 2002), enacted on October 3, 2002, the Office of Atomic Energy for Peace was renamed the "Office of Atoms for Peace" (OAP) under the Ministry of Science and Technology. ${ }^{1)}$

In 2003, the Ministry of Science and Technology has issued two ministerial regulations to set forth the criteria for protecting individuals, society and the environment from radiation hazards, both for the present and in the future; Ministerial Regulation on Licensing Requirements and Procedures B.E. 2546 (A. D. 2003) and Ministerial Regulation on Radioactive Waste Management B. E. 2546 (A. D. 2003). The major requirement of this amendment is to reduce allowable radiation exposure limits for workers and public to be in accordance with the recent international standards (ICRP-60). The amendment also clarifies regulatory procedures to make them more convenient for practice.

During 2004 and 2005, OAP updated some regulations and reorganized the administrative structure by separating the utilization of nuclear energy unit from the regulatory unit, to ensure clear separation of the regulatory and management roles, according to IAEA safety standards. The Thailand Institute of Nuclear Technology (TINT) was thus established. A public organization, TINT is responsible for research and development of nuclear technologies while OAP became the regulatory authority responsible for establishing rules, regulations, and oversight of implementation of the safety measures at nuclear facilities. ${ }^{1)}$

In 2007, the Ministry of Science and Technology revised the Ministerial Regulation on Licensing Requirements and Procedures B. E. 2546 (A. D. 2003) to a new Ministerial Regulation on Licensing Requirements Procedures and Nuclear Material, By-Product or Atomic Energy Processing B. E. 2550 (A. D. 2007). The objective for the amendments was to make them consistent to the current IAEA standards.

As a result of evolutionary development of nuclear legislation system, now we have a structured system of regulatory documents, which can be illustrated by the chart as Fig. 1.

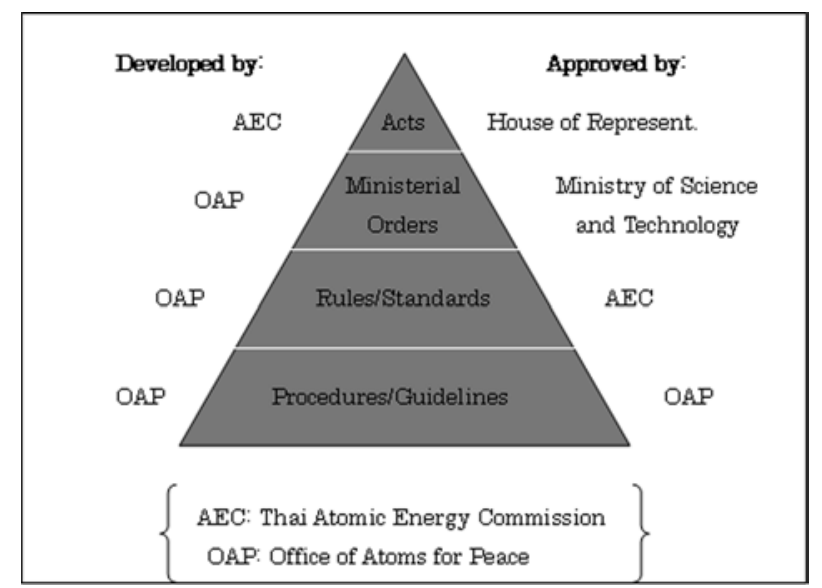

Fig. 1 Regulatory documents in Thailand. 


\section{Roles of AEC \& OAP}

Under the Atomic Energy for Peace Act, the Commission has a clear mandate to establish and enforce health, safety, security and environmental protection standards in the nuclear field. The objectives of the Commission also include overseeing of compliance with Thai's international commitments regarding nuclear non-proliferation, safeguards and security. Additionally, AEC was charged to provide objective scientific, technical and regulatory information to the public about its activities and, more general, about the effects of the nuclear industry on health, safety and the environment.

Thai AEC consists of 15 sub-committees. The major of these are the sub-committee for Medical Application, Agricultural Application, Industrial Application, Nuclear Law, Food Processing Technology, Licensing of Radioisotopes and Nuclear Materials, Reactor Safety (adaption of Regulatory and Safety Standard for Nuclear Power Plant and Reactor Safety). ${ }^{2)}$

The missions of the OAP are responsible for policy development and for safety regulations involving the utilization of atomic energy in compliance with international standards, which will include: ${ }^{1)}$

(1) To be the secretariat of the Thai Atomic Energy Commission for Peace.

(2) To regulate the radiation, nuclear, and nuclear material safety

(3) To formulate policies and strategic plans on peaceful application of atomic energy, as well as to coordinate the plans and hence move towards realistic practice.

The Commission is given the authority to enact regulation of the atomic energy use, to ensure public safety, to facilitate research and development in the field of nuclear technology, and to provide technical support to the users of nuclear technologies to comply with safety regulations.

\section{OAP's ACTIVITIES}

OAP is the main national institution for safety studies, research and development, dissemination of information on atomic energy, regulation, control, as well as promotion civil atomic energy use in Thailand.

In fiscal year 2005, the Radiation Safety Regulation Committee issued 1,612 licenses for nuclear materials and byproducts to many organizations benefiting from medical, industrial, research and development, and other applications. ${ }^{1)}$ OAP performs function of the technical support organization for the AEC. The applications are submitted to the OAP and the staff evaluates radiation safety and the conditions of the safe use of nuclear materials, by reviewing the Applicant's documents and/or inspecting actual radiation working sites, as well as taking the technical conditions of equipment and buildings into consideration. In the case of positive outcome from the review process, OAP submit the evaluation report to the AEC with a recommendation to issue the license.

Furthermore, OAP also conducted other activities to promote and support the radiation safety program in order to guarantee safety for the workers and the public, as well as to keep abreast with international standards. These activities include formulating action plans, monitoring and approving action plans for radioactive material transportation, coordinating in case of radiation emergency, inspection in case of radiation incident at a working site, development regulations and policies concerning radiation source utilization in various applications, hosting conferences/seminars and public hearing, informing related personnel on rules and regulations, as well as advising on and disseminating the knowledge on matters related to radiation protection.

\section{THE STATUS OF NUCLEAR PROGRAM IN THAILAND}

In Thailand, of nuclear technology, radioisotopes, and radiation techniques have valid applications in many fields including agriculture, industry and medicine. Examples in the medical field include the use of radiation from cobalt-60 in cancer treatments, the treatment of cervical cancer by iridium-192 and tantalum-182, the use of iodine-131 to treat hyperthyroidism, analysis of blood circulation by indium-113m and technetium- $99 \mathrm{~m}$, the use of radiation in sterilization of medical supplies and pharmaceuticals including syringe needles, bandages, cotton swabs and Thai herbal medicine. In terms of agricultural applications, radiation is used for microbial decontamination and insect disinfestations of many food and agricultural products.

On October 30, 2007, the Thai Cabinet approved conceptual plan to create the infrastructure for nuclear power generation. So far, this plan is limited to the creation of the necessary infrastructure for Thailand's future nuclear power sector, e.g., preparation of human resources, establishing an administrative office, and etc. The decision about construction of first nuclear power plant has not been made yet, so the issue still remains open for the next government. The Cabinet approved the plan in principle, and appointed the Committee to prepare a feasibility study on nuclear power generation. Also, the Cabinet approved establishment of an office for nuclear power project under the Ministry of Energy. A first portion of budget $(1,800 \text { million baht }=51 \text { million } \$)^{3)}$ is to be allocated from the Energy Conservation Fund for implementation of the plan in 2008-2010, which covers the establishing of the project office, development of law amendments, improvement of regulatory system, commercial and industrial structure plans, a nuclear safety plan, environmental protection assessment, public relations and acceptance. Major legislative developments are expected concerning the revision of the Atomic Energy for Peace Act. Currently the Act concerns the use radioactive substances, import and export, and regulations, but it is not fully is applicable for nuclear power generation, because it did not support for the licensing and regulatory control of nuclear installations.

On November 20, 2007, the Thai Cabinet approved the draft new Atomic Energy for Peace Act for revision of Atomic Energy for Peace Act B. E. 2504 (A. D. 1961) which is to set forth objectives for protecting individuals, society and the environment from radiation hazards, both for the present and in the future. The new legislation and regulation will cover both licensing of radiation sources and nuclear materials; the licensing requirements for all activities related to the siting, 
construction and operation of a nuclear installation; and to specify facilities, activities and materials that are the subject for regulatory control.

\section{CONCLUSION}

At large, the national regulations reflect international practice, however with minor variations that account for the specifics of Thai policy and political culture. License applicants must provide detailed information concerning the substance or device or activity for which they request a license. This information include description of the methods, procedures, and equipment to be used to carry on the licensed activity at normal conditions, as well as during or after accidents, to monitor nuclear substance releases, to detect and record radiation and to limit the spread of radioactive contamination within and beyond the site boundaries. Information is also required on the methods, procedures and equipment used to calibrate radiation survey meters and dosimeters and to conduct leak tests and surveys as well as on equipment and system inspection programs, instructions for dealing with accidents, worker training programs and a number of other safety related matters.

The Commission is empowered under the Act to designate trained inspectors who are authorized to inspect nuclear facilities and places where nuclear substances, prescribed equipment and information may be kept, for the purpose of verifying compliance with the Act, any regulation, order, or decision made under the Act, or any license condition. Amongst other things, inspectors are empowered to order a licensee to take any measures considered necessary to protect the environment, health and safety of workers and population, to maintain national security, and compliance with Thai's international obligations.

The legislation is also cover safety standards to comply with the International Atomic Energy Agency. The Thai Cabinet provides the Commission with authority to execute regulatory functions. The OAP, an executive body of Thai AEC, provides technical support, expertise, and performs some regulatory functions delegated by the AEC. The Ministerial regulations have been revised, and new law and ministerial regulation have been drafted to suit present situation, especially for licensing activities.

\section{REFERENCES}

1) Office of Atoms for Peace; An Energy for Creativity, ISBN: 974-229-937-4, p. $22-35$ (2006). Thailand.

2) L. Siripirom; Nuclear Legislation in Thailand, p. 7 (2007). FNCA nuclear legislation, Thailand.

3) P. Pongwanan; Surayud cabinet lays foundation for Thailand's nuclear power, p. 1 (2007). www.prachatai.com.

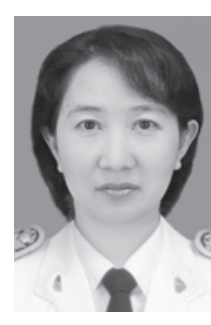

\section{Apisara CharoensRI}

Nuclear Chemist, Radioactivity Monitoring Group, Bureau of Technical Support for Safety Regulation, Office of Atoms for Peace (OAP), Bangkok, Thailand. Exchange Researcher (2007), Kosako's Lab, Department of Nuclear Engineering and Management, Graduate School of Engineering, the University of Tokyo, Japan.

E-mail: apisara@oaep.go.th 